\title{
Putting the 'Place' in Place-Based Climate Action: Insights from Climate Adaptation Initiatives Across Scotland
}

\author{
Ellie Murtagh and Matthew Lane
}

Highlights Understanding and responding to the unique context and challenges of places is fundamental to the success of place-based adaptation projects.

Keywords Place $\cdot$ Climate adaptation $\cdot$ Partnerships $\cdot$ Scotland

\section{INTRODUCTION}

This chapter critically examines the concept of 'place' in relation to locally situated climate adaptation projects in order to better understand how this concept is being interpreted, negotiated and acted upon by practitioners. As evidenced by the contributions throughout this book, there is currently a groundswell of interest in focusing on 'place' as a scale

\footnotetext{
E. Murtagh

Sniffer/University of Strathclyde, Glasgow, Scotland, UK e-mail: ellie@sniffer.org.uk

(C) The Author(s) 2022

C. Howarth et al. (eds.), Addressing the Climate Crisis, https://doi.org/10.1007/978-3-030-79739-3_2
} 
through which to deliver climate action projects and engender more climate literate individuals and communities. Following on from government discourse around place-making, the idea of place-based engagement with climate change and sustainability governance is gaining traction (PCAN, 2019; Vallance et al., 2019). Despite this, however, to date, little attempt has been made to understand how the concept of 'place' is understood by already existing climate action projects, and the role that place has played as an organising principle for coordinating action among co-located stakeholders.

To make an initial attempt at remedying this oversight, the chapter first briefly engages with the academic literature on the idea of place and place identity as well as emerging thoughts on their application to climate change adaptation specifically. Drawing on original qualitative research, the chapter briefly outlines the research project's methodological underpinning before discussing findings from interviews with lead practitioners from four adaptation initiatives in Scotland. We use these projects to ground some initial thoughts regarding the need to recognise the importance of place as a complex and value-laden mobiliser for collective climate action at a local scale.

\section{Place in the Literature}

The concept of 'place' is largely ineffable but is variously drawn upon to try and capture the complex interaction of agencies, objects and relationships which give meaning to particular locations. In turn, appreciation of the concept and the assigning of value to what it represents for individuals and communities can powerfully shape identity and attachment to particular places. The concept of place identity was first proposed by Proshansky (1978) who defined it as 'dimensions of self that define the individual's personal identity in relation to the physical environment by means of a complex pattern of conscious and unconscious ideas, beliefs, preferences, feelings, values, goals and behavioural tendencies and skills relevant to this environment' (Proshansky, 1978, p. 155). Paasi (1986) further developed the concept of place identity through distinguishing

M. Lane $(\varangle)$

School of Geosciences, University of Edinburgh, Edinburgh, Scotland, UK e-mail: matthew.lane@ed.ac.uk 
two separate facets of place identity, be that (i) the place identity of a place, which relates to how places are presented, promoted, identified or distinguished from other places through nature, culture, geography and history of that place; or (ii) people's place identity which pertains to how individuals exist within a place and their 'sense of place'. Place identity can thus influence behaviours and activities as well as individual and collective well-being.

More recently, it has been argued that place identity has particular relevance to climate change adaptation. Climate impacts will always be felt the strongest by individuals and communities most 'local' to those impacts. The more attached and embedded the relationships between those people and the places in question, the more devastating the impacts are likely to be. Fresque-Baxter and Armitage (2012) highlight that adaptation often focuses on the material assets required to build adaptive capacity, with less consideration to the nonmaterial or subjective facets of adaptation such as identity, belief or values. Value-based approaches can help explore what people value most about their everyday lives and how these social values are likely to be affected by environmental changes. It therefore seeks to redress the emphasis of adaptation planning on physical impacts by putting the lifestyle and wellbeing attributes that matter most to communities at the centre of adaptation planning (David et al., 2017, p. 167).

Place-based adaptation is interpreted within this chapter as actions which involve shaping, developing or enhancing a 'place' in response to current and projected climate change, whilst contributing to a broader context of change and social and ecological justice. Such actions, however, have had limited review or testing within empirical studies (Peng et al., 2020). With the aim of providing insight which can better inform future climate action projects seeking to pro-actively draw upon the idea of 'place' as an organising principle, in what follows we engage with four place-based adaptation initiatives in Scotland.

\section{Case Study and Methods}

The Scottish policy landscape encourages place-based ways of working. The Scottish Government have adopted 'The Place Principle', which promotes a shared understanding of place and the need for a collaborative approach to a place's services and assets to improve outcomes for communities as well as contributing to the achievement of collective outcomes 
of Scotland's National Performance Framework (Scottish Government, 2019). The Community Empowerment Act also enables communities to have greater involvement in local decision-making by placing Community Planning Partnerships (CPPs) on a statutory footing to plan and deliver local outcomes.

Place-based working in Scotland is diverse in practice ranging from holistic explorations of place to focused initiatives on a specific issue, such as climate adaptation. The Climate Change (Scotland) Act 2009 requires a Scottish Climate Change Adaptation Programme (SCCAP) and also makes climate adaptation a statutory requirement for all Scottish public bodies, with mandatory reporting of progress. As a result of policy levers for place-based working and climate adaptation action alongside an increasing recognition of the importance of place, there are a growing number of place-based adaptation initiatives emerging.

In this chapter, we draw on semi-structured scoping interviews with the project leaders of four such initiatives, in order to understand the idea of 'place' as an organising concept. The projects explored were: Highland Adapts, Climate Ready Clyde, Climate Ready Aberdeenshire and Dundee Climate Action, defined in Table 2.1. The studied projects were all initiated by local government but are undertaken in partnership with wider stakeholders including community members, public and private organisations, in order to co-design local action plans. Sniffer, a Scottish sustainability charity, has been involved in some extent in all four projects, ranging from technical advice and capacity building through to providing secretariat support.

Interview questions explored (i) the interpretation and use of the concept of place within the various place-based adaptation projects, (ii) how variations in place have been identified and addressed through partnership projects and (iii) current appreciations for a sense of place among those participating in adaptation activities. Interview recordings were transcribed and thematic analysis drawn upon to identify emerging patterns within the data. Interview quotes are anonymised. To note, the views expressed in interviews reflect only those of the interviewees and are not meant to represent the way place is understood collectively by stakeholders involved with the respective projects. For the purposes of this short chapter, we are simply interested in how the concept of place is thought about and understood by those with important organising roles in 'place-based' climate action projects. 
Table 2.1 Overview of place-based adaptation projects studies

\begin{tabular}{|c|c|}
\hline Initiative & Description \\
\hline Climate Ready Aberdeenshire & $\begin{array}{l}\text { Climate Ready Aberdeenshire is a collaborative } \\
\text { initiative to create Aberdeenshire's climate change } \\
\text { adaptation and mitigation strategy. It brings together } \\
\text { the views and expertise of a range of diverse } \\
\text { stakeholders from communities, public, private and } \\
\text { 3rd sector organisations, to set out how to work } \\
\text { together to meet the challenges of a changing climate } \\
\text { within Aberdeenshire, aiming to launch the Climate } \\
\text { Ready Strategy in } 2022\end{array}$ \\
\hline Climate Ready Clyde & $\begin{array}{l}\text { Climate Ready Clyde is a cross-sector initiative funded } \\
\text { by the Scottish Government and } 15 \text { member } \\
\text { organisations to create a shared vision, strategy and } \\
\text { action plan for an adapting Glasgow City Region }\end{array}$ \\
\hline Dundee Climate Action & $\begin{array}{l}\text { In June 2019, Dundee Council declared a Climate } \\
\text { Emergency, recognising the serious and accelerating } \\
\text { environmental, social and economic challenges faced } \\
\text { by climate change. To respond to this challenge, a } \\
\text { partnership Climate Action Plan has been prepared } \\
\text { which has been the culmination of collaborative work, } \\
\text { led by Dundee City Council and co-designed with } \\
\text { public, private and community organisations, } \\
\text { recognising that a concerted city-wide effort is } \\
\text { required. The Plan includes four themes of Energy, } \\
\text { Transport, Waste and Resilience }\end{array}$ \\
\hline Highland Adapts & $\begin{array}{l}\text { The Highland Adapts initiative brings organisations } \\
\text { from across the Highland region together to develop } \\
\text { a unique approach to adapting to climate change. } \\
\text { Jointly resourced and rooted in a deep understanding } \\
\text { of the needs and priorities of communities, the } \\
\text { initiative will develop a strong evidence base setting } \\
\text { out the climate risks and opportunities that are } \\
\text { affecting the Highlands. This evidence will be used to } \\
\text { develop a shared adaptation strategy and action plan } \\
\text { which will embed action to adapt across } \\
\text { organisational, community and sector plans, strategies } \\
\text { and investments }\end{array}$ \\
\hline
\end{tabular}

\section{Findings from Practice}

\section{The Concept of Place in Existing Place-Based Adaptation Projects}

The four place-based adaptation projects explored here come from across Scotland and encompass rural, urban, coastal and highland environments. All project leads interviewed were cognisant of the diverse senses of 'place' 
that exist even within the areas they work. The feedback from practitioners presents an idea of 'place' interpreted as a multifaceted concept comprised of intersections of people, nature, built environment, culture, history and emotions in relation to a specific location. Place, in their opinion, supports the development of senses of identity, connections and feelings from interactions with or interpretations of the place; however, these may differ across individuals, communities and regions based on lived experience, demography or local geography.

The recognition of differing experiences and interpretations of 'place' was used to justify needing to think about place as a concept when undertaking situated climate action projects. All interviewees expressed strong feeling towards the need to work differently in each local place. Interviewees felt that a one-size-fits-all approach simply would not work, due to the specific challenges resulting from geographic, economic and demographic factors. Likewise, they felt that to explore and overcome these multiple perspectives, there was need to speak to people to develop a collaborative and joint view on what place means in the context of taking action against climate change. It was argued that this must be driven by and for the community, as those that live there know best what they want and need, as highlighted by one interviewee.

A place-based approach helps because you're getting the views of individual people in that place... and the needs or challenges of each place are different, and you are actually taking that into account. It builds better engagement and relations to people in those places if you get to understand how they live and how they work, and not just paint them all with the same brush.

It was stressed by interviewees how both place and climate change are emotive subjects and need to be recognised and treated as such if they are to complement one another effectively. Interviewees felt that one cannot and should not take a non-emotional approach to adaptation.

[You] can't not take an emotional response as climate change will impact lives, livelihoods, where people live, fundamentally for foreseeable future.

Focusing on a specific place acts as a mechanism to highlight the emotional, symbolic, spiritual and perceived intrinsic values of the environment. It is proposed by Adger et al. (2011) that climate change policy 
underemphasises the symbolic and psychological aspects of places and risk to them. This may be addressed through creating space and opportunity to share and discuss emotions.

One of the key things about place is the intersect between culture and history...so many future challenges to adaptation are rooted in the past, whether that is from economic development to post-industrial legacy to issues with housing, stubborn social problems around health and vulnerability.

\section{Place as an Organising Principle for Building Partnerships}

All of the initiatives recognised the role of place, but not all had as of yet explored it methodically within the project. Activities so far were mainly high-level approaches ranging from community-wide surveys to inform the development of Highland Adapts; stakeholder workshops with participants across the public, private, third and community sectors to inform the Dundee Climate Action Plan; to the creation of a Theory of Change outlining a vision for a Climate Ready Glasgow City Region and necessary elements required to achieve it through the Climate Ready Clyde programme.

The ability to build understanding of different views and what place means collectively to frame wider discussion about the need to adapt was identified as to how the concept of place can be an enabler for climate change adaptation. Place was seen to make climate change impacts more tangible. A place-based approach can also enable identification of places or communities most 'at risk' of climate impacts and work to prioritise and support them.

Understandings of place, however, are arguably inseparable from broader multi-level influences of power, politics and policy that shape engagement with place. Macro-level decision-making about investments in place can lead to discord within areas that haven't received similar financial investment, in turn fostering a sense of disconnectedness to place which can hamper possibilities of 'place' as an enabler for climate action. An example of this was provided by a Scottish city experiencing massive regeneration in some areas, whilst other parts have persistently high levels of multiple deprivation.

Similarly, a noted barrier was tension in interpretations of place and the challenges in building and reaching consensus. The presence and activity 
of place-based adaptation partnerships were identified as mechanisms to overcome this challenge through participative processes with representative stakeholders. A multi-stakeholder approach can bring together stakeholders and community members to highlight important aspects of place, help co-design plans and shape activity. Place-based adaptation initiatives are seen to help create and anchor institutions in the process. In this respect, they can also help build and strengthen relationships. Interviewees felt, however, that whilst there may be different outcomes sought by each partner, the most important aspect of a joined-up approach is that the partnership is a collective listener to the needs and aspirations of the community and use their voice to shape overall response and enhance delivery.

\section{Appreciating the Diverse (and Constantly Changing) Power of Place}

Exploring, understanding and responding to the unique context and challenges of different places was seen as fundamental to the success of the place-based adaptation projects. In addition to this understanding, however, and in lieu of the fully integrated, joined-up approach to place-making reflected upon above, interviewees highlighted the need to appreciate the shifting relationships to place captured by any particular project scope. For example, interviewees felt that there is often a regional collective sense of identity, whilst simultaneously there are unique and bespoke senses of identity at the more local, community scale. For instance, within the area of Aberdeenshire, the identity of being from the 'Shire' and how this differentiated the lived experience of being from the 'city' (Aberdeen) was highlighted as providing a shared sense of identity, seeing a large region as one; whilst it was also noted that within the Highlands there are different senses of places across communities and even within a singular community, different sense of place exists.

In a similar vein, the onset of the COVID-19 pandemic during 2020 powerfully illustrates the way in which place attachment and identity can shift and evolve over time as well as from location to location. For example, interviewees suggest that the pandemic-associated lockdowns encouraged people to explore their local place in a lot more depth and potentially led to an increased appreciation for what's on the doorstep: 
You are much more focused on your immediate environment obviously, because that's now where you go for entertainment, exercise, food, health...everything!

It's forced us to think quite deeply about what are the characteristics of a place that we value.

With regard to adaptation, these evolving relationships to place exhibit a very literal form of adaptation, further demonstrating its status as a constant process of change, rather than something that can simply be 'done' in a particular location at a particular point in time.

The pandemic has had significant benefit (to a point) in increasing people's awareness of their place and its associated advantages and limitations... [communities] have already been through a life changing emergency and can tap into feelings and experiences that they've gone through... to be prepared for future emergencies.

\section{Conclusion: Lessons for 'Place-Based' Climate Action Projects}

Places are shaped by services, assets, natural and economic resources, history, geography and environmental change as well as by the needs of the people who live there. Place-based adaptation projects offer a way to integrate ongoing activities, needs and local priorities to ensure a location is resilient to climate impacts as well as minimising the burden of diverse pressures which may be exacerbated under a changing climate. The motivation to further advance place-based adaptation is driven by the potential to create better places that retain their culture, identity and importance to those who live there and will be affected by the impacts of climate change.

Findings presented in this chapter highlight how an understanding of 'place' can enhance climate action projects. In accordance with the wider ambitions of this edited collection, the reflections from place-based adaptation project leads are presented here as potential learnings for others seeking to mobilise the concept of place as a tool for coordinating local action against climate change. However, given the context-specificity of the people-place-adaptation nexus discussed through this chapter, it would be counter-productive to provide specific recommendations for how place(s) should be engaged with by climate action projects. What the 
chapter has hoped to achieve, however, is a raising of awareness regarding what a greater appreciation for place may do to spur adaptation.

We argue here that this appreciation takes two contrasting yet equally important forms. Firstly, that place is a concept which has the potential to disrupt and undermine aspirations for climate action if practitioners are not acutely aware of the powerful (and diverse) ways in which people feel and experience attachment to certain locations. Secondly, that place can offer an organising principle which can be actively drawn upon to highlight already existing relationships between co-located stakeholders and between those stakeholders and the threats posed by climate change. As suggested by one interviewee, the success of climate adaptation projects will in large part be determined by local adaptive capacity. The complex nature of the relationship between adaptive capacity and 'place' thus calls for further research engagement. In the meantime, the more cognisant we are of the powerful and multifaceted ways in which particular places shape our collective understanding of climate change, the more likely it is that we will be able to take effective actions.

\section{REFERENCES}

Adger, W. N., Barnett, J., Iii, F. S. C., \& Ellemor, H. (2011, May). This must be the place : Underrepresentation of identity and meaning in climate change decision-making. Global Environmental Politics, 1-26.

David, T., Graham, S., John, C., \& Stephen, C. (2017, July). Advancing valuesbased approaches to climate change adaptation : A case study from Australia. Environmental Science and Policy, 76, 113-123. https://doi.org/10.1016/j. envsci.2017.06.014

Fresque-Baxter, J. A., \& Armitage, D. (2012). Place identity and climate change adaptation: A synthesis and framework for understanding. Wiley Interdisciplinary Reviews: Climate Change, 3(3), 251-266. https://doi.org/10.1002/ wcc. 164

Paasi, A. (1986). The institutionalization of regions: A theoretical framework for understanding the emergence of regions and the constitution of regional identity. Fennia, 164(1), 105-146. https://doi.org/10.11143/9052

PCAN. (2019). Available online: https://pcancities.org.uk/what-local-climatecommission

Peng, J., Strijker, D., \& Wu, Q. (2020, March). Place identity: How far have we come in exploring its meanings? Frontiers in Psychology, 11, 1-19. https:// doi.org/10.3389/fpsyg.2020.00294 
Proshansky, H. (1978). The city and self-identity. Environment and Behaviour, $10(2), 147-169$.

Quinn, T., Lorenzoni, I., \& Adger, W. N. (2015, January). Place attachment, identity, and adaptation. The Adaptive Challenge of Climate Change, 160-170. https://doi.org/10.1017/CBO9781139149389.010

Scottish Government. (2019). Place principle: Introduction [Online]. https:// www.gov.scot/publications/place-principle-introduction/

Vallance, P., Tewdwr-Jones, M., \& Kempton, L. (2019). Facilitating spaces for place-based leadership in centralized governance systems: The case of Newcastle City Futures. Regional Studies, 53(12), 1723-1733.

Open Access This chapter is licensed under the terms of the Creative Commons Attribution 4.0 International License (http://creativecommons.org/licenses/ by $/ 4.0 /)$, which permits use, sharing, adaptation, distribution and reproduction in any medium or format, as long as you give appropriate credit to the original author(s) and the source, provide a link to the Creative Commons license and indicate if changes were made.

The images or other third party material in this chapter are included in the chapter's Creative Commons license, unless indicated otherwise in a credit line to the material. If material is not included in the chapter's Creative Commons license and your intended use is not permitted by statutory regulation or exceeds the permitted use, you will need to obtain permission directly from the copyright holder.

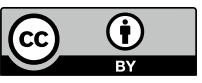

